\title{
Prospective analysis of psychological differences between adult and elderly cancer patients during postoperative adjuvant chemotherapy
}

\author{
M. M. Muñoz-Sánchez ${ }^{1}$ (1) - C. Calderon ${ }^{2} \cdot$ P. Jimenez-Fonseca ${ }^{3}$ - M. C. Soriano-Rodríguez ${ }^{1} \cdot$ C. Jara ${ }^{4} \cdot$ T. García-García $^{5}$.

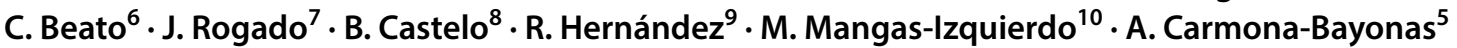

Received: 1 April 2018 / Accepted: 21 May 2018

๑) Federación de Sociedades Españolas de Oncología (FESEO) 2018

\begin{abstract}
Purpose Despite the burgeoning geriatric population with cancer and the importance of understanding how age may be related to mental adjustment and quality of life so far, differences in coping strategies and psychological harm between the elderly and adults are hardly being taken into account to modify the approach to this population. The aim of this prospective study is to describe the differences in psychological characteristics between older and adult cancer patients and examine dissimilarities in their psychological evolution during adjuvant chemotherapy.

Methods Adults (18-69 years old) and older patients ( $\geq 70)$ with newly diagnosed non-metastatic resected cancer admitted to receive adjuvant chemotherapy were recruited. Patients completed the following questionnaires: mini-mental adjustment to cancer, brief symptom inventory, shared decision-making questionnaire-patient's version, multidimensional scale of perceived social support, EORTC quality-of-life instrument, life orientation test-revised, and satisfaction with life scale.

Results 500 cancer patients (394 adults and 106 older) were evaluated. The impact of the diagnosis was less negative among older patients, with no differences in coping strategies, quality of life, or search for support. Regarding psychological changes from the beginning to the end of the adjuvant treatment, both age groups reported more somatic symptoms, increased psychological difficulty, reduced coping strategies, and a significant decrease in quality of life at the end of postoperative chemotherapy.

Conclusion Although there were clear psychological differences between adults and senior cancer patients, their evolution during adjuvant chemotherapy was similar, with deterioration in quality of life and coping. This negative psychological impact of adjuvant chemotherapy should be taken into account when considering interventions.
\end{abstract}

Keywords Cancer $\cdot$ Coping $\cdot$ Elderly $\cdot$ Psychological adaptation $\cdot$ Quality of life $\cdot$ Shared decision-making

P. Jimenez-Fonseca

palucaji@hotmail.com

1 Department of Medical Oncology, Hospital Virgen de La Luz, Cuenca, Spain

2 Department of Clinical Psychology and Psychobiology, Faculty of Psychology, University of Barcelona, Barcelona, Spain

3 Department of Medical Oncology, Hospital Universitario Central de Asturias, Avenida Roma sn. 33011, Oviedo, Spain

4 Department of Medical Oncology, Hospital Universitario Fundación Alcorcón, Universidad Rey Juan Carlos, Madrid, Spain
5 Department of Hematology and Medical Oncology, Hospital Universitario Morales Meseguer, Murcia, Spain

6 Department of Medical Oncology, Hospital Universitario Virgen de La Macarena, Sevilla, Spain

7 Department of Medical Oncology, Hospital Universitario La Princesa, Madrid, Spain

8 Department of Medical Oncology, Hospital Universitario La Paz, Madrid, Spain

9 Department of Medical Oncology, Hospital Universitario de Canarias, Tenerife, Spain

10 Department of Medical Oncology, Hospital Galdakao-Usansolo, Galdakao-Usansolo, Spain 


\section{Introduction}

The diagnosis of cancer usually arrives abruptly causing psychological distress in almost all patients, with feelings of uncertainty, hopelessness, vulnerability, fear, anxiety, and sadness. The patient is forced to assume a new identity as a cancer patient, originating changes in the labor, economic, and psychosocial spheres. All this requires a major adjustment effort, besides adaptation will influence the outcome of the disease [1].

In early stage cancer, adjuvant treatment has improved in recent years to reduce recurrence and mortality [2]. Hence, issues concerning quality of life (QoL) during and after cancer treatment have become increasingly important. Good supportive care, including the biopsychosocial setting, and the backing of families, is critical to overcome cancer and cope with chemotherapy.

Furthermore, cancer is a significant health issue in older persons. It is estimated that $43 \%$ of all new cases and more than $60 \%$ of cancer mortality will occur in persons aged $\geq 70$ years [3]. Moreover, senior cancer patients tend to receive less aggressive treatment, due to the fear of an increased risk of treatment-related complications [4-9]. The development of comorbidities and the accelerated loss of autonomy can make older adults with cancer more vulnerable $[6,10,11]$. On one hand, age influences the vital, physical, mental, and family situation of patients, affecting their adaptation to the disease. On the other hand, recent studies suggest that age may serve as a protective factor; for instance, older people are more prone to emotional repression [8], stoicism, acceptance of death, greater religious coping, and adjustment based on passive resignation [9].

Despite the burgeoning geriatric population with cancer and the importance of understanding how age may be related to mental adjustment and QoL so far, differences in clinical course, coping strategies, and psychological harm between older and adults are hardly being taken into account to modify the approach to this population. In this background, the aim of this study is to ascertain the differences in clinicopsychological characteristics between older and adult patients treated with adjuvant chemotherapy after surgical resection of a cancer. We also examine distinctiveness in their psychological evolution during chemotherapy treatment.

\section{Materials and methods}

\section{Design and patients}

A prospective, cross-sectional, multi-center study (NEOcoping) was conducted from July 2015 to July 2017 in
15 medical oncology departments in different hospitals throughout Spain.

Eligible patients were $\geq 18$ years who had undergone surgery on their cancer in the month prior to the start of adjuvant chemotherapy. Old patients were considered those aged $\geq 70$ years. Patients with dementia or any other serious mental illness that prevented survey comprehension were excluded. The study was approved by the Ethics Review Board at each institution and by the Spanish agency of medicines and medical devices (AEMPS). The study was based on the completion of various questionnaires and data collection procedures were similar for all hospitals. Participation was voluntary, anonymous, and would not affect patient care.

\section{Variables}

Data on demographic and clinical characteristics (age; gender, marital status; education level; occupational sector; tumor site and stage; and time since diagnosis) were collected for statistical purposes through a web-based platform (www.neocoping.es).

Mini-mental adjustment to cancer (M-MAC) is a short and refinement version of the original MAC [10] scale, one of the most widely used instruments to measure coping responses in individuals with cancer. M-MAC contains 29 items grouped into five coping strategies: helplessness-hopelessness, anxious preoccupation, cognitive avoidance, fatalism, and fighting spirit. Anagnostopoulos et al. proposed two second-order factors: 'adaptive' (fighting spirit, cognitive avoidance, and fatalism subscales) and 'maladaptive' coping (helplessness-hopelessness and anxious preoccupation subscales) [11]. The test-retest reliability ranged from 0.62 to 0.99 . Cronbach's alpha ranged from 0.78 to 0.93 [10].

Brief symptom inventory (BSI)-18 includes 18-item divided into three dimensions (somatizations, depression, and anxiety) [12]. The somatization dimensions (six items) assess: discomfort produced by the perception of corporal disorders including cardiovascular, stomach, and muscular problems; depression dimension (six items) assess: symptoms commonly related to depression, such as apathy, sadness, and thoughts of suicide; and anxiety dimension (six items) assess: feelings of fear, general nervousness, and even panic. Global symptom index (GSI) summarizes the respondent's overall emotional adjustment or psychological distress. Respondents were asked to answer in relation with how they had felt the last 7 days, and each item was rated on a 5-point Likert scale from 0 (not at all) to 4 (extremely). The test-retest reliability ranged from 0.78 to 0.90 . Internal consistency (Cronbach's alpha) ranged from 0.81 to 0.90 [12].

Shared decision-making questionnaire-patient's version (SDM-Q-9) contains 9-item and evaluates the SDM 
process from the patient's perspective [13], and are scored on a 6-point Likert scale ranging from 0 (completely disagree) to 5 (completely agree). It was adapted and validated to Spanish by De las Cuevas et al. [24]. A total raw score of between 0 (lowest level of SDM) and 45 is possible. SDMQ-9 reveals a high Cronbach alpha in German (0.98), US (0.94), and Spanish samples (0.88) of patients with chronic diseases.

Multidimensional scale of perceived social support (MSPSS) includes 12-item related to three sources of social support: family, friends, and significant other [14]. Responses are provided using scales that range from 1 (strongly disagree) to 7 (strongly agree).

European Organization for Research and Treatment of Cancer QoL questionnaire instrument (EORTC QLQ-C30) is based on 30 individual items summarized in five functioning scales: physical functioning, role functioning, emotional functioning, social functioning, and cognitive functioning and nine symptom scales, e.g., pain, dyspnea, sleep disturbance, appetite loss, and diarrhea $[15,16]$. The patient is requested to rank each of the items on a scale ranging from 1 (not at all) to 4 (very much).

SDM Questionnaire-Physician's version (SDM-Q-Doc) evaluates the physician's perspective and how well they follow SDM with their patients [17]. The questionnaire consists of nine items, each of which describes one step of the process. The items are scored on a 6-point Likert scale from 0 (completely disagree) to 5 (completely agree). A total raw score of between 0 (lowest level of perceived SDM) and 45 is calculated by adding the scores of all items. The SDM-QDoc presented good internal consistency and reliability in German $(\alpha=0.88)$ [17].

Life orientation test revised (LOT-R) evaluates optimism and pessimism scales, with ten items (three items assess optimism, three items assess pessimism, and there are four filler items) [18]. Respondents indicated the extent to which they agreed with each item on a 5-point Likert scale that ranged from 1 (strongly disagree) to 5 (strongly agree). Internal consistency varies between 0.74 and 0.78 [18].

Satisfaction with life scale (SWLS) consists of five item and was developed as a measure of the judgmental component of subjective well-being. Participants indicate how much agree or disagree with each of the five items using a 7-point scale that ranges from 7 (strongly agree) to 1 (strongly disagree). The internal consistency $(\alpha=0.86)$ was found to be high [19].

\section{Statistical analyses}

Descriptive statistics were used to summarize demographic data and survey responses. Absolute frequencies were presented for categorical data and mean and standard deviation (SD) were used for quantitative data. Additional descriptive analyses were performed grouping patients by age. The bivariate Chi-square and $t$ tests were performed to assess the differences between elderly and non-elderly patients in some sociodemographic, clinical, and psychological characteristics. Analysis of variance (ANOVA) of repeated measures was performed taking into account the scores obtained before and after chemotherapy adjuvant treatment. The statistical analyses were run on the IBM-SPSS 23.0 statistical software package (SPSS, INC., Chicago, III) for Windows PC.

\section{Results}

\section{Characteristics of population}

The final group consisted of 394 adult patients with cancer and 106 older patients. Disease and treatment variables are presented in Table 1. The mean age was 54.2 and 74.3 years, respectively.

Among adult patients, the percentage of women was higher ( 66 vs $53 \%, \chi^{2}=12.196, p<0.001$ ), they had higher level of education $\left(\chi^{2}=9.142, p<0.001\right)$ and more were employed (50 vs 7\%, $\chi^{2}=63.187, p<0.001$ ) than in the elderly group. In both groups, the percentage of married or living with a partner was similar.

Regarding the type of cancer, non-elderly patients presented mainly breast cancer (39\%) followed by colorectal cancer $(37 \%)$, while the elderly presented mainly colorectal cancer $(52 \%)$ followed by breast cancer in $15 \%$. Most adult patients had stage I-II disease (59\%), while senior patients had predominantly stage III cancer (56\%), with significant differences in both groups $(p=0.003)$. The risk of recurrence was also higher in cancers of older group $\left[t_{(498)}=-2.747\right.$, $p=0.007]$. Significant differences were found in adjuvant treatment, the therapy of choice in the elderly was mainly mono-chemotherapy, whereas in younger patients, it was polychemotherapy combined with radiotherapy in $41 \%$. The time until diagnosis was slightly higher in non-elderly adults than in older adults, although there were no significant differences in both groups.

\section{Psychological adaptation to cancer}

Differences in psychological adaptation process by cancer type and patient's age is reported in Table 2.

Cancer diagnosis Impact of the cancer diagnosis was less negative among older than adult cancer patients $\left[t_{(495)}=2.544, p=0.001\right.$, Cohen's $\left.d=0.296\right]$. Adult cancer patients experienced the diagnosis more negatively, with more symptoms of anxiety, depression, and somatization than older cancer patients. 
Table 1 Characteristics of adult and elderly patients

\begin{tabular}{|c|c|c|c|c|c|}
\hline Characteristics of patients & $\begin{array}{l}\text { Total } \\
(n=500)\end{array}$ & $\begin{array}{l}\text { Adults } \\
\text { with cancer } \\
(n=394)\end{array}$ & $\begin{array}{l}\text { Elder } \\
\text { with cancer } \\
(n=106)\end{array}$ & $T / \chi^{2}$ & $p$ \\
\hline Gender: $n(\%)$ & & & & 12.196 & 0.001 \\
\hline Women & $309(62)$ & $259(66)$ & $56(53)$ & & \\
\hline Men & $191(38)$ & $135(34)$ & $56(47)$ & & \\
\hline Age: years, mean (SD) & $58.5(12.2)$ & $54.2(10)$ & $74.3(3.5)$ & -32.784 & 0.001 \\
\hline \multicolumn{6}{|l|}{ Marital status: } \\
\hline Married/partnered: $n(\%)$ & $385(77)$ & $306(78)$ & $80(75)$ & 0.277 & 0.599 \\
\hline Others & & $88(22)$ & $26(25)$ & & \\
\hline \multicolumn{6}{|l|}{ Educational level: $n(\%)$} \\
\hline Basic & $288(58)$ & $213(54)$ & $75(70)$ & 9.142 & 0.002 \\
\hline Medium & $212(42)$ & $181(46)$ & $31(30)$ & & \\
\hline Unemployed: $n(\%)$ & $290(58)$ & $195(50)$ & $99(93)$ & 63.187 & 0.001 \\
\hline \multicolumn{6}{|l|}{ Localization of cancer: $n(\%)$} \\
\hline Colorectal & $201(40)$ & $146(37)$ & $55(52)$ & 23.205 & 0.001 \\
\hline Breast & $170(34)$ & $154(39)$ & $16(15)$ & & \\
\hline Others & $129(26)$ & $344(24)$ & $95(33)$ & & \\
\hline \multicolumn{6}{|l|}{ Stage: $n(\%)$} \\
\hline I-II & $277(55.4)$ & $232(59)$ & $47(44)$ & 9.080 & 0.003 \\
\hline III & $207(41.4)$ & $150(38)$ & $59(56)$ & & \\
\hline $\begin{array}{l}\text { Time since diagnosis: days, } \\
\text { mean (SD) }\end{array}$ & $85.2(127)$ & $89.1(130)$ & $71(113)$ & 1.168 & 0.243 \\
\hline \multicolumn{6}{|l|}{ Type of treatment: $n(\%)$} \\
\hline $\mathrm{CT}+$ surgery & $318(64)$ & $234(59)$ & $84(79)$ & 14.233 & 0.001 \\
\hline $\mathrm{CT}+$ surgery $+\mathrm{RT}$ & $182(36)$ & $160(41)$ & $22(21)$ & & \\
\hline Risk of relapse & $42.9(23.2)$ & $41.3(22.5)$ & $48.7(24.9)$ & -2.747 & 0.007 \\
\hline
\end{tabular}

$C T$ chemotherapy, $R T$ radiotherapy, $S D$ standard deviation
Coping with cancer and QoL Both groups mainly used adaptive coping strategies, the two most used were the fighting spirit and fatalism, while hopelessness was the least used. There were no significant differences in QoL nor in the search for social support, and both groups received support mainly from the family and the social environment.

SDM Medical oncologists were more satisfied in SDM with adult patients than with the elderly $\left[t_{(498)}=2.127\right.$, $p=0.034$, Cohen's $d=0.247]$. Patients, meanwhile, feel remarkably satisfied with SDM, without significant differences between age groups.

\section{Psychological change after adjuvant treatment}

To study the psychological change produced by cancer treatment, repeated measures ANOVA was performed taking into account the scores obtained before and after adjuvant treatment of the cancer applied to 207 of the patients. This reduction of the sample was due to the fact that only these subjects had already finished adjuvant treatment during the course of this study. The results for the dimensions of the BSI18, Mini-MAC, and EORTC QLQ-C30 scales are shown in Table 3 and Fig. 1.
Both age groups reported more somatic symptoms $\left[F_{(1205)}=45.271, p<0.001, \eta=0.181\right]$, and greater psychological distress at the end of treatment $\left[F_{(1205)}=9.046\right.$, $p=0.003, \eta=0.048]$. As for the coping strategies, both groups reduced the adaptive $\left[F_{(1205)}=5.961, p=0.016\right.$, $\eta=0.016]$ and maladaptive strategies $\left[F_{(1205)}=11.610\right.$, $p=0.001, \eta=0.056]$. From adaptive strategies, the fighting spirit and fatalism diminished, and cognitive avoidance remained stable and of the maladaptive strategies, both groups diminished helplessness-hopelessness and anxious preoccupation.

Regarding the QoL, adult and senior patients reported a significant decrease in their QoL at the end of the adjuvant treatment in symptom scale $\left[F_{(1203)}=14.166, p<0.001\right.$, $\eta=0.065]$, health status $\left[F_{(1203)}=5.026, p=0.026\right.$, $\eta=0.025]$, and in $\mathrm{QoL}\left[F_{(1137)}=9.526, p=0.002, \eta=0.046\right]$.

\section{Discussion}

In this study, we analyzed psychological resources and their evolution through adjuvant chemotherapy in senior and adult cancer patients. The adult group is formed 
Table 2 Comparison of clinical-psychological characteristics and scales between adult and elderly patients

\begin{tabular}{|c|c|c|c|c|c|}
\hline Clinical-psychological characteristics & $\begin{array}{l}\text { Adults } \\
\text { with cancer } \\
(n=394)\end{array}$ & $\begin{array}{l}\text { Older } \\
\text { with cancer } \\
(n=106)\end{array}$ & $T$ & $p$ & Effect size \\
\hline Psychological distress scale (BSI-18) ${ }^{\mathrm{a}}$ & $64.8(6.7)$ & $62.9(6.1)$ & 2.544 & 0.011 & 0.296 \\
\hline Anxiety & $62.6(7.7)$ & $60.2(6.9)$ & 2.870 & 0.004 & 0.328 \\
\hline Depression & $61.1(6.0)$ & $59.7(5.8)$ & 2.225 & 0.027 & 0.237 \\
\hline Somatization & $61.6(6.9)$ & $60.2(5.8)$ & 2.140 & 0.034 & 0.220 \\
\hline \multicolumn{6}{|l|}{ Coping with cancer scale (M-MAC) } \\
\hline Adaptive & $66.5(16.5)$ & $67.9(16.3)$ & -0.769 & 0.442 & - \\
\hline Maladaptive & $31.5(19.1)$ & $31.0(20.6)$ & 0.237 & 0.813 & - \\
\hline \multicolumn{6}{|l|}{ Social support scale (MPSS) } \\
\hline Familial & $25.6(3.8)$ & $26.1(2.9)$ & -1.243 & 0.215 & - \\
\hline Friends & $23.6(5.3)$ & $22.6(5.0)$ & 1.798 & 0.073 & - \\
\hline Social & $25.8(3.8)$ & $25.6(3.8)$ & 1.319 & 0.188 & - \\
\hline \multicolumn{6}{|l|}{ QoL scale (EORTC QLQ-C30) } \\
\hline Functional scale & $40.8(11.7)$ & $38.4(12.4)$ & 1.844 & 0.066 & - \\
\hline Symptom scale & $39.7(11.9)$ & $38.2(10.9)$ & 1.180 & 0.238 & - \\
\hline Health status & $74.1(17.7)$ & $73.7(18.9)$ & -0.227 & 0.820 & - \\
\hline QoL & $35.5(11.9)$ & $34.4(11.8)$ & 0.863 & 0.388 & - \\
\hline \multicolumn{6}{|l|}{ Shared decision-making scale } \\
\hline Version physician (SDM-doc) & $91.2(9.3)$ & $88.8(10.1)$ & 2.127 & 0.034 & 0.247 \\
\hline Version patient (SDM-Q-9) & $82.1(19.2)$ & $82.4(19.2)$ & -0.143 & 0.887 & - \\
\hline
\end{tabular}

${ }^{\mathrm{a}} \mathrm{T}$ score

Table 3 Results of the multivariate analysis of variance repeated measures

\begin{tabular}{|c|c|c|c|c|c|c|c|c|c|}
\hline & \multicolumn{2}{|c|}{ Adults cancer } & \multicolumn{2}{|l|}{ Older cancer } & \multicolumn{2}{|l|}{ Total } & \multirow{2}{*}{$\begin{array}{l}\text { Time } \times \text { age } \\
F\end{array}$} & \multirow{2}{*}{$\begin{array}{l}\text { Age } \\
F\end{array}$} & \multirow{2}{*}{$\begin{array}{l}\text { Time } \\
F\end{array}$} \\
\hline & Pre & Post & Pre & Post & Pre & Post & & & \\
\hline $\begin{array}{l}\text { Psychological dis- } \\
\text { tress scale (BSI) }\end{array}$ & $64.8(7.1)$ & $66.0(6.8)$ & $63.6(5.8)$ & $66.2(7.4)$ & $64.6(6.8)$ & $66.0(6.9)$ & 1.385 & 0.204 & $9.046^{* *}$ \\
\hline Anxiety & $62.0(7.9)$ & $60.9(7.0)$ & $59.6(6.6)$ & $60.6(8.3)$ & $61.4(7.7)$ & $60.9(7.3)$ & 3.706 & 1.598 & 0.000 \\
\hline Depression & $61.1(6.2)$ & $60.8(6.0)$ & $59.5(5.8)$ & $60.6(6.0)$ & $60.7(6.1)$ & $60.8(6.0)$ & 1.974 & 1.250 & 0.683 \\
\hline Somatization & $61.2(6.8)$ & $65.9(7.1)$ & $60.1(5.6)$ & $63.6(7.1)$ & $61.0(6.5)$ & $65.4(7.1)$ & 0.963 & 3.368 & 45.271 ${ }^{* *}$ \\
\hline \multicolumn{10}{|c|}{ Mental adjustment to cancer (M-MAC) } \\
\hline Adaptive & $65.6(18.1)$ & $60.7(18.6)$ & $67.8(16.1)$ & $65.8(21.1)$ & $66.1(17.6)$ & $61.9(19.3)$ & 1.023 & 1.772 & $5.961^{*}$ \\
\hline Maladaptive & $33.1(19.9)$ & $25.6(19.7)$ & $27.9(19.5)$ & $25.6(21.1)$ & $31.9(19.9)$ & $25.6(20.0)$ & 3.286 & 0.721 & $11.610^{* *}$ \\
\hline \multicolumn{10}{|c|}{ QoL scale (EORTC-QLQ-C30) } \\
\hline Functional scale & $40.3(11.6)$ & $42.3(13.9)$ & $39.7(14.4)$ & $41.7(14.3)$ & $40.1(12.3)$ & $42.2(13.9)$ & 0.004 & 0.105 & 3.472 \\
\hline Symptom scale & $39.0(10.8)$ & $43.2(13.5)$ & $38.4(10.1)$ & $42.1(13.5)$ & $38.9(10.6)$ & $42.9(13.5)$ & 0.050 & 0.271 & $14.166^{* *}$ \\
\hline Health status & $24.7(17.4)$ & $29.9(21.0)$ & $27.1(18.9)$ & $30.5(16.9)$ & $25.2(17.7)$ & $30.0(20.1)$ & 0.218 & 0.303 & $5.065^{*}$ \\
\hline Quality of life & $34.6(11.5)$ & $38.7(12.9)$ & $35.7(12.5)$ & $38.4(11.9)$ & $34.9(11.7)$ & $38.6(12.7)$ & 0.370 & 0.046 & $9.526 * *$ \\
\hline
\end{tabular}

Mean (standard deviation)

Pre the scores obtained before adjuvant chemotherapy, Post the scores obtained after adjuvant treatment of the cancer

${ }^{*} p<0.01$

${ }^{* *} p<0.001$

mostly by women, with a higher level of education, and working. In contrast, patients in the older group tend to be men, with a basic level of education and are mostly retired (93\%). There are several reasons for these differences: patients aged $\geq 70$ years were born during the Spanish civil war (1936-1939) or in the post-war period, which implied a precarious economic situation and a less access 
Fig. 1 Scores obtained in questionnaires before (pre) and after (post) adjuvant chemotherapy: Brief Symptom Inventory (BSI18), Mini-Mental Adjustment to Cancer (M-MAC) and European Organization for Research and Treatment of Cancer qualityof-life questionnaire instrument (EORTC-QLQ-C30) before and after adjuvant treatment applied to 207 of the patients
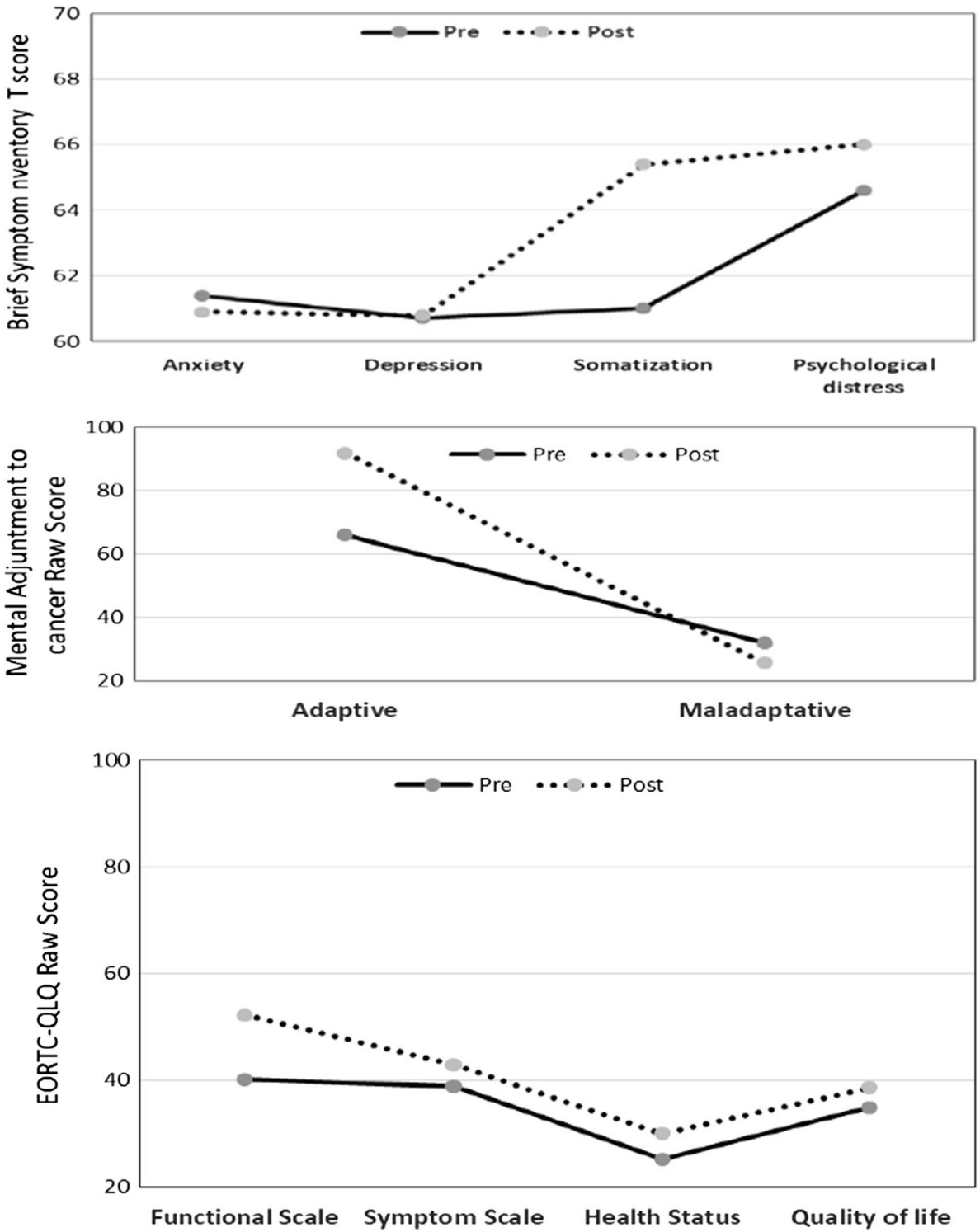

to formal education; regarding the employment rate, the average retirement age in our country is 65 years old.

With respect to the type of cancer, adult patients had mainly breast cancer followed by colorectal cancer and older patients usually had colorectal cancer, followed by breast cancer. Although the time to diagnosis did not differ significantly between the two groups, most adult patients were diagnosed in early stages (stages I and II), with lower risk of recurrence, and older patients were mostly in stage III with higher risk for relapse. This may reflect the fact that the age of population screening for breast cancer in Spain is up to 69 years and screening for colorectal cancer is not yet fully established. In addition, older people take longer to consult when they have symptoms and this delays the diagnosis.

Adult patients most frequently received combined multimodality treatment. Nevertheless, elderly patients are mainly treated with surgery and mono-chemotherapy and less radiotherapy. Previous studies indicate that older cancer patients are much often undertreated [20,21]. The main reasons at the origin of undertreatment were a higher prevalence of co-morbidity, shorter life expectancy, absence of an elderly population in clinical trials, and increased adverse effects of treatment. However, there are elderly patients with good general condition and without comorbidities, so adjuvant treatments should be adapted to the older patient's general health status and offer the best chance of cure in each case [4-6].

Regarding psychological adjustment to cancer, younger patients cope worse with the disease, as they present more anxiety, depression, somatic symptoms, and psychological distress than older ones. There are several explanations for why psychological adjustment increases with age [22, 23]. This may be because older people are more likely to take their lives on the basis of 'here and now', to have a 
greater life perspective and more experiences than younger people, what some call 'psychological immunization' that would help them to live cancer from a different vital perspective. In addition, young people face a vital situation in which other age-related roles take center stage, such as caring for work, children, and parents, and that can increase stress on cancer [22]. There were no differences in the use of adaptive coping strategies between both age groups; the two most used were the fighting spirit and fatalism, while hopelessness was the least used. This is rather similar to the results of the previous research conducted only in older adult by Deimling et al. [24]. In our series, older people showed a tendency toward greater emotional regulation. QoL data and social support were similar and this was received mainly from the family and the social environment in both groups.

Even though medical oncologists appear to be more comfortable in communicating with younger patients, both groups of patients were very satisfied with SDM, showing no real barriers depending on age. This situation should be more difficult in a different scenario as for example in the metastatic setting [25].

Adult patients experienced a more optimistic view about cancer and prognosis than older ones. Other authors as Deimling et al. have also shown this perspective in cancer-related worries in elderly longer survivors [26]. As a result, while older patients better accepted the diagnosis with less psychological distress, they were more pessimistic about treatment and prognosis.

Concerning psychological change after adjuvant treatment, both age groups reported more somatic symptoms and greater psychological distress at the end of adjuvant chemotherapy, with no differences between the two groups. Regarding the coping strategies, both groups reduced the adaptive and maladaptive strategies. As for QoL, both adult and older patients reported a clinically relevant decrease in their QoL after the chemotherapy was completed. This is also reflected in previous studies only in elderly population by Puts et al. [27] and Fitzpatrick et al. [28].

The fundamental limitation of this study is inherent in its cross-sectional design, which makes it difficult to explore the dynamic nature of the clinical-psychological processes and their variability during adjuvant chemotherapy. Besides, the information after completion of chemotherapy could only be obtained in 207 patients.

To conclude, we would like to emphasize that despite clear psychological differences between adult and older cancer patients, their evolution during adjuvant chemotherapy was similar.

Acknowledgements With gratitude to all the patients participating and to all the medical oncologists collaborating in this study.
Funding source The study was supported by the FSEOM-Onvida for Projects on Long Survivors and Quality of Life. SEOM (Spanish Society of Medical Oncology) 2015

\section{Compliance with ethical standards}

Conflict of interest None to declare. This is an academic study.

Ethical approval The study has been performed in accordance with the ethical standards of the Declaration of Helsinki and its later amendments. This study is an observational trial without intervention.

Informed consent Signed informed consent was obtained from all patients.

\section{References}

1. Fawzy FI, Fawzy NW, Arndt LA, Pasnau RO. Critical review of psychosocial interventions in cancer care. Arch Gen Psychiatry. 1995;52(2):100-13.

2. Kemetli L, Rutqvist LE, Jonsson H, Nyström L, Lenner P, Törnberg S. Temporal trends in the use of adjuvant systemic therapy in breast cancer: a population based study in Sweden 1976-2005. Acta Oncol. 2009;48(1):59-66.

3. Xie L, Semenciw R, Mery L. Cancer incidence in Canada: trends and projections (1983-2032). Health Promot Chronic Dis Prev Can. 2015;35(1):2-186.

4. Bouchardy C, Rapiti E, Blagojevic S, Vlastos AT, Vlastos G. Older female cancer patients: importance, causes, and consequences of undertreatment. J Clin Oncol. 2007;25(14):1858-69.

5. Mehta RD, Roth AJ. Psychiatric considerations in the oncology setting. CA Cancer J Clin. 2015;65(4):300-14.

6. Llorente-Vizcaíno A, Cejudo-Bolívar JC. Memories and Alzheimer's disease. Rev Neurol. 2001;32(12):1163-72.

7. Kurtz ME, Kurtz JC, Stommel M, Given CW, Given B. Physical functioning and depression among older persons with cancer. Cancer Pract. 2001;9(1):11-8.

8. Rodríguez E, Pinto JL. The social value of health programmes: is age a relevant factor? Health Econ. 2000;9(7):611-21.

9. Jacobsen PB. Improving psychosocial care in outpatient oncology settings. J Natl Compr Canc Netw. 2010;8(4):368-70.

10. Pereira MG, Baia V, Machado JC. Coping and quality of life in patients with skin tumors in the follow-up stage: the mediating role of body image and psychological morbidity. J Psychosoc Oncol. 2016;34(5):400-12.

11. Anagnostopoulos F, Kolokotroni P, Spanea E, Chryssochoou M. The Mini-Mental Adjustment to Cancer (Mini-MAC) scale: construct validation with a Greek sample of breast cancer patients. Psychooncology. 2006;15(1):79-89.

12. Derogatis LR, Melisaratos N. The brief symptom inventory: an introductory report. Psychol Med. 1983;13(3):595-605.

13. Cuevas DL, Peñate C, Perestelo-Pérez L, Serrano-Aguilar P. Shared decision making in psychiatric practice and the primary care setting is unique, as measured using a 9-item Shared Decision Making Questionnaire (SDM-Q-9). Neuropsychiatr Dis Treat. 2013;9:1045-52.

14. Zimet GD, Powell SS, Farley GK, Werkman S, Berkoff KA. Psychometric characteristics of the Multidimensional Scale of Perceived Social Support. J Pers Assess. 1990;55(3):610-7.

15. Koller M, Aaronson NK, Blazeby J, Bottomley A, Dewolf L, Fayers $\mathrm{P}$, et al. Translation procedures for standardised quality of life questionnaires: the European Organisation for Research 
and Treatment of Cancer (EORTC) approach. Eur J Cancer. 2007;43(12):1810-20.

16. Aaronson NK, Ahmedzai S, Bergman B, Bullinger M, Cull A, Duez NJ, et al. The European Organization for Research and Treatment of Cancer QLQ-C30: a quality-of-life instrument for use in international clinical trials in oncology. J Natl Cancer Inst. 1993;85(5):365-76.

17. Scholl I, Kriston L, Dirmaier J, Buchholz A, Härter M. Development and psychometric properties of the shared decision making questionnaire-physician version (SDM-Q-Doc). Patient Educ Couns. 2012;88(2):284-90.

18. Scheier MF, Weintraub JK, Carver CS. Coping with stress: divergent strategies of optimists and pessimists. J Pers Soc Psychol. 1986;51(6):1257-64.

19. Diener ED, Emmons RA, Larsen RJ, Griffin S. The satisfaction with life scale. J Pers Assess. 1985;49(1):71-5.

20. Ashkanani F, Eremin O, Heys SD. The management of cancer of the breast in the elderly. Eur J Surg Oncol. 1998;24(5):396-402.

21. Kennedy BJ. Needed: clinical trials for older patients. J Clin Oncol. 1991;9(5):718-20.

22. Blank TO, Bellizzi KM. A gerontologic perspective on cancer and aging. Cancer. 2008;112(11):2569-76.
23. Schroevers MJ, Ranchor AV, Sanderman R. The role of age at the onset of cancer in relation to survivors' long-term adjustment: a controlled comparison over an 8-year period. Psychooncology. 2004;13(10):740-52.

24. Deimling GT, Wagner LJ, Bowman KF, Sterns S, Kercher K, Kahana B. Coping among older-adult, long-term cancer survivors. Psychooncology. 2006;15(2):143-59.

25. Delgado-Guay MO, De La Cruz MG, Epner DE. 'I don't want to burden my family': handling communication challenges in geriatric oncology. Ann Oncol. 2013;24(7):30-5.

26. Deimling GT, Brown SP, Albitz C, Burant CJ, Mallick N. The relative importance of cancer-related and general health worries and distress among older adult, long-term cancer survivors. Psychooncology. 2017;26(2):182-90.

27. Puts MT, Monette J, Girre V, Wolfson C, Monette M, Batist G, et al. Quality of life during the course of cancer treatment in older newly diagnosed patients. Results of a prospective pilot study. Ann Oncol. 2011;22(4):916-23.

28. Fitzpatrick TR, Edgar L, Holcroft C. Assessing the relationship between physical fitness activities, cognitive health, and quality of life among older cancer survivors. J Psychosoc Oncol. 2012;30(5):556-72. 